\title{
Negotiating informal elder care, migration and exclusion: the case of a Turkish immigrant community in Belgium
}

\author{
By Wouter De TAVERNIER ${ }^{1}$ \& VeERLE DRAULANs ${ }^{2}$
}

\begin{abstract}
In this article, we analyse the role exclusion plays in three theories explaining the provision of informal care for the elderly: norms and roles (sociological institutionalism), the availability and accessibility of formal care (rational choice institutionalism) and concerns about balancing time and money (rational choice theory). Feeding into the discussion on agency in old-age exclusion literature, we argue that exclusion shapes informal care provision in all three theories: social exclusion enforces norms, civic exclusion hinders appropriate formal care provision and economic exclusion reduces the opportunity costs of informal care. Hence, exclusion structures positions and power relations in care negotiation processes. The study shows that exclusion should not only be analysed as an outcome but also as a force shaping the life conditions of older people. The argument is supported using data from qualitative interviews with stakeholders in informal elder care in a Turkish immigrant community in Belgium. Intersections of gender, generation and migration status are taken into account.

Keywords: elder care, migration, exclusion, gender, generations.

${ }^{1}$ Wouter De Tavernier, Centre for Comparative Welfare Studies, Department of Political Science, Aalborg University, Denmark

${ }^{2}$ Veerle Draulans, Centre for Sociological Research, KU Leuven, Belgium
\end{abstract}


International Journal of Ageing and Later Life

In the current age of political austerity, there has been a trend towards the re-familialisation of elder care, meaning that the responsibility for care is increasingly being shifted back to the family (Bywaters et al. 2018; Leitner 2003; Tõnurist \& De Tavernier 2017). In Flanders (Belgium) as elsewhere, the government has set out to encourage informal caregiving to older individuals. These policy decisions seem to negate the findings of many studies about the detrimental consequences for informal carers, known as informal caregiver burden (Chiao et al. 2015). Moreover, whereas informal care is often presented as a matter of social inclusion (e.g. Koops \& Kwekkeboom 2005; see also the Active Ageing Index, in which care to older adults is considered "participation in society", UNECE 2017), we argue in this article that it is deeply rooted in inequality and systems of exclusion. Hence, through shifting care responsibilities to the family, policymakers in fact use and exacerbate existing inequalities and forms of exclusion.

Inequality and exclusion have been the topic of several studies in the field of elder care. Typically, they focus on inclusion and exclusion as outcomes of care, with good care having the potential to promote the inclusion of older individuals in society (Dahlberg \& McKee 2016; Gregory et al. 2017; Poscia et al. 2018), yet at the same time informal care can create inequalities and lead to the exclusion of caregivers (Greenwood et al. 2018; Sutcliffe et al. 2017; Van Houtven et al. 2013). Rather than looking at how care affects exclusion, this article explores the reverse relationship: which role does exclusion, particularly of (potential) caregivers, play in the phase when decisions about elder care need to be negotiated? Accordingly, this article feeds into literature dealing with the structural aspects affecting the gendered division of labour, as well as the unequal gender norms they are rooted in. However, we aim to go beyond the general discussion on gender inequalities and care and argue that exclusion is a core mechanism through which informal care can be organised or even guaranteed. By combining three theories commonly used in social policy literature to explain informal care, with insights from literature on old-age exclusion, we show how the exclusion of older individuals and their caregivers, or the threat thereof, paradoxically seems to contribute to individuals taking up elder care responsibilities. We consider this paradoxical, because caregiving is typically considered a form of inclusion, 
not exclusion (supra). However, as Walsh and colleagues (2017) point out, more than being about contact, exclusion is about being denied agency (Saunders 2008; Walsh et al. 2017; Warburton et al. 2013). Hence, this study shows how exclusion in some areas limits agency in caregiving.

The argument is illustrated using data from a qualitative study on elder care in a Turkish community in Belgium. Because social, civic and economic exclusion in old age are particularly pronounced in immigrant communities (e.g. Lee et al. 2014), these communities offer an ideal opportunity to examine the relationship between exclusion and informal care. Hence, the article also aims to contribute to literature concerning elder care in immigrant communities by linking the three theories discussed to characteristics prevalent in immigrant communities. In particular, we investigate how social and economic positions, cultural dispositions and civic participation of the members of the community affect the organisation of elder care within the community.

The three theories are linked though the perspective of negotiating care. Rather than affecting elder care outcomes directly, as the theories would assume, we maintain that each of them affects individuals' positions and power within negotiations. Given this focus on positions and power, an intersectional approach (Crenshaw 1989; de Vries 2015) is essential in this study. Different categories are paid attention to in the analysis, notably the intersections of gender, generations, migration status and economic position.

\section{Case Study}

This article is based on a qualitative case study of the Turkish community in the town of Genk, Belgium (Flanders). Genk offers an interesting case for a number of reasons. As a former mining town, $55 \%$ of the population in the town is of foreign origin; $18 \%$ of inhabitants are of Turkish descent (Stad Genk 2018). Because "guest workers" were assumed to eventually return to their home countries, little or no effort was made to integrate first-generation immigrants, for instance through language courses. Moreover, given the large local Turkish community in Genk and the fact that Turkey has one common national language, learning the local language was not essential in daily life, 
International Journal of Ageing and Later Life

particularly for women, who rarely worked outside the household. Mining as an activity also shaped the community: many men of the first generation passed away relatively early from mining-related illnesses, resulting in an older generation with a disproportionate share of widowed women (Stad Genk 2018). After the closure of the mines in 1987, the town suffered another economic blow when a large car manufacturing plant employing around 6000 individuals was closed in 2014, a year before the interviews for this study were carried out, causing a spike in local unemployment. The town of Genk is also known for its elder care policies. Being awarded the title of "care-friendly municipality" (Middelbos 2010), the local government promotes elder care, in particular informal care, with supportive services for caregivers and supplementary care benefits.

Between April and December 2015, we interviewed 22 individuals involved in the organisation of informal elder care in Genk, and two external key individuals, using semi-structured interviews guided by a topic list. After transcription of all the interviews, we systematically brought together quotes dealing with the same themes in a coding scheme. Coding was further refined through supplementary labelling. Initially we searched for stakeholders involved in the organisation of informal care in the Turkish community through purposive sampling, after which we looked for further potential interviewees through snowball sampling. In Genk, we interviewed 18 women and four men. Ten of them, all of Turkish descent (nine women and one man), were informal carers for parents. They combined a professional occupation with informal caregiving activities, except for one woman who was unemployed. Interviewees were engaged in a wide range of professions, such as medical doctors (4), nurses (5), policymakers (2) and civil servants or social welfare workers (7). The interviews with policymakers, civil servants or social welfare workers, all professionally active in Genk, were necessary to obtain information about the specific local social policies that could be relevant in the organisation of elder care. We did not interview older individuals of the first generation. Even though it was initially part of the research design, it quickly became clear that it was an unreasonable expectation. Given their limited knowledge of the Dutch language, an interpreter would have been 
Negotiating informal elder care, migration and exclusion

necessary during these interviews. Several interviewees told us that the first generation would either refuse to talk to us or would paint an idealised picture of elder care in the Turkish community out of distrust and a feeling of being controlled, exacerbated by the presence of an interpreter. We therefore decided to focus only on the perspective of caregivers and of stakeholders who could contribute to or facilitate informal care negotiations.

\section{Informal Elder Care, Migration and Exclusion: Constructing a Theory}

In social policy literature, informal elder care outcomes have been explained from three different perspectives. In one theoretical framework, generally described as sociological institutionalism, informal elder care is seen as the result of cultural factors, especially norms and roles about the gendered division of labour (Pfau-Effinger 2005; Pfau-Effinger \& Rostgaard 2011). A second strand of research, rational choice institutionalism, understands informal elder care as the outcome of policies, in particular related to the availability and accessibility of formal care. As rational actors, individuals set policies that are of benefit to them and make use of these policies in a rational way (Peters 2012). Whereas both institutionalisms try to bridge the macro and micro level, the third theory, rational choice theory, remains at the micro level. Here, individuals are utility maximisers, basing their decisions on balancing time and money. Informal elder care, then, is the result of considerations of costs and the opportunity costs of formal and informal care (Blau et al. 2010: 89; Hakim 2000). However, in many concrete instances, we could expect different outcomes based on these three theories. Moreover, tensions may emerge within theories, because norms are not uniformly shared in society (Pfau-Effinger \& Rostgaard 2011). An additional perspective is therefore required that can mediate the effects of these three theories on informal care delivery. The negotiating care perspective (Conlon et al. 2014; McGraw \& Walker 2004; Zechner \& Valokivi 2012) offers this possibility. We accordingly argue that rational choice theory and the two institutionalisms do not impact informal care directly but that they instead affect the positions and power relations in the negotiations about care. 
International Journal of Ageing and Later Life

Our goal is threefold. Firstly, we aim to present an integrated account of all three theories stemming from social policy literature, by bringing in the negotiating care perspective. Secondly, we argue that exclusion is at the very core of all three theories, although in different domains (Walsh et al. 2017), and thus it is a central concept in the analysis of informal care. Thirdly, we set out to theorise elder care in immigrant communities by linking specific characteristics of these communities to the theories presented, accordingly illustrating the role exclusion plays in informal care decisions. A schematic overview of how immigrant communities are linked to care theories is presented in Figure 1.

Figure 1. Schematic overview of the proposed theoretical framework.

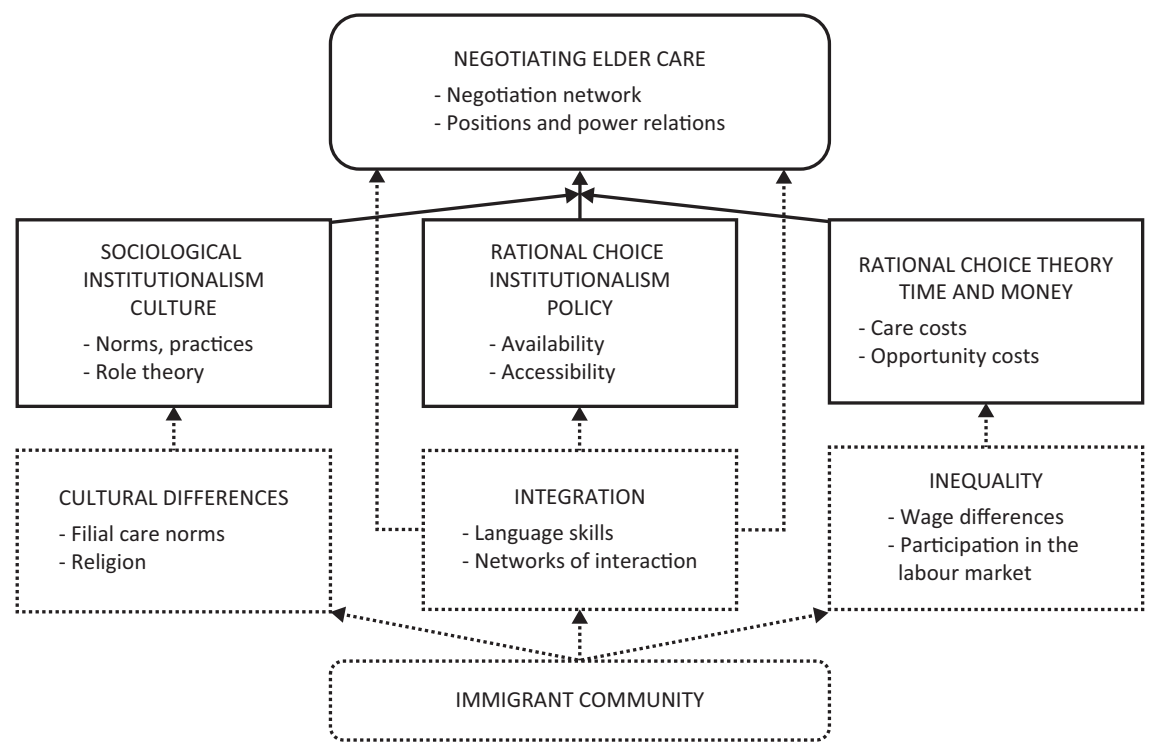

Note: the solid lines refer to the integration of existing elder care theories; the dotted lines indicate how they are related to realities in immigrant communities. 


\section{Sociological Institutionalist Perspective and Exclusion}

From a sociological institutionalist perspective (Hall \& Taylor 1996, 2007), individuals are rule-followers in that their actions are determined by shared ideas in the community. Here, the term institutions refers to informal institutions, such as norms, values and shared beliefs and practices that shape individuals' actions. Sociological institutionalism revolves around the concept of appropriateness: individuals decide how to act based on ideas about which behaviours are considered appropriate or "the normal thing to do" for a specific person in a specific situation (March \& Olsen 1989, 2006). Norms entail these informal rules about which behaviour is considered appropriate. Rule-following can result from internalisation of these norms through socialisation processes, in which case the individual will voluntarily follow the norm because he or she considers this the appropriate thing to do.

Ideas about the motivation for informal elder care in the Turkish immigrant community were discussed during each interview, depending on the specific position of the interviewee. We find numerous examples of this perspective, stating that individuals are rule-followers in that their actions are determined by shared ideas in the community. Quite a few interviewees considered taking responsibility for informal elder care to be a moral obligation, but several cited different arguments to explain why this was the case: ${ }^{1}$

Something that plays an important role is the moral obligation to look after your parents. Whereas it would be wrong to say that this obligation doesn't exist in Flanders, it has been more loosely interpreted over the last 20 to 30 years. (I11)

\footnotetext{
${ }^{1}$ Interviewees were assigned a number so that it is clear whether or not quotes come from the same or different individuals. To ensure anonymity, we limit the information about interviewees cited to the following: (I1) medical doctor, man, Belgian origin; (I2) medical doctor and informal carer, woman, Turkish origin; (I3) external key interviewee regarding Turkish elder care, woman, Turkish origin; (I4) social welfare worker and informal carer, woman, Turkish origin; (I5) nurse, woman, Turkish origin; (I6) nurse and informal carer, woman, Turkish origin; (I7) social welfare worker and informal carer, woman, Turkish origin; (I8) nurse, woman, Belgian origin; (I9) informal carer, woman, Turkish origin; (I10) woman, non-Belgian and non-Turkish origin; (I11) social welfare worker, woman, Belgian origin; (I12) social welfare worker and informal carer, woman, Turkish origin.
} 
International Journal of Ageing and Later Life

Sometimes that responsibility was inspired by the idea of reciprocity:

Well, our parents looked after us for so long; now it is our turn to do the same for them. That is the feeling experienced very strongly by the children, actually: "It is our duty, we need to look after our parents as well as we can, we need to do more than our very best." [...] Yes, your parents look after you the whole of their lives, and after a while the roles are reversed, aren't they? (I2)

On other occasions, interviewees argued that the obligation was rooted in religion or culture:

It is partly inspired by culture, partly by religion, and our faith dictates that we must continue to look after our parents until the end. (I3)

For example, when a parent - how can I put it - is unhappy, not satisfied with the care and the love you give, then God can punish you for it. So that is something we need to take into account. It is also a matter of respect in our culture. After all, your father has worked hard for you, fed you, given you a roof over your head and protected you. Your mother carried you for nine months and raised you, so it is only normal that we show them respect. That is what they learned from their parents and we have learned it from them. (I4)

These quotes illustrate strong care norms of children towards their parents: children have a responsibility to care for their dependent parents, whether this responsibility stems from religion, culture or reciprocity. These norms are strongly gendered, confirming that informal elder care is rooted in "filial care norms": the expectation that daughters deliver care to their parents (Lowenstein et al. 2004; Pfau-Effinger 2005). Studies find some notable differences in these filial care norms between natives and non-Western immigrants in Western Europe, the latter having more pronounced expectations towards their daughters to take up care responsibilities when they become dependent (de Graaf \& Francke 2003; de Graaf et al. 2012). The strongly gendered nature of care expectations also came to the fore during the interviews:

Where are the sons then, in this story? Well, they are only there for the financial side of things. Sons will also come and help when there is administrative work, or something that needs to be arranged. (I5) 
Negotiating informal elder care, migration and exclusion

\begin{abstract}
Yes, having a cleaner was a luxury, because after all, I was always expected to clean my parents' home, from top to bottom, including all the windows. Every week, every month, with an in-depth clean every three months. All of it used to be my job. They never asked a cleaner to do it, they did not want a cleaner to do it because they used to say: "I have a daughter. Why should I ask someone else to do it when I have children?" (I4)

But I think that my brothers would have struggled with looking after my mum, that is true. My mother never used to like it either, to have a male carer. "It is a man, I don't want that man. Get a woman instead for me." (I4)
\end{abstract}

However, when the norms and values of an individual do not correspond to those of others in the community, individuals can be forced to follow the rule anyway through sanctioning. Typically, social exclusion (Walsh et al. 2017) is the sanctioning mechanism though which norm-following is enforced: individuals breaking the rules are stigmatised and pushed into marginalised social positions by the others in the community, inflicting feelings of shame (Durkheim 1964). Accordingly, the community not only penalises the individual, but also sets an example to others that such rule breaking will not be tolerated (Berger \& Luckmann 1966: 80). In conclusion, social norms are, to the extent that they have not been internalised, upheld through social exclusion or the fear thereof, which generates social pressure to follow the rules.

The social pressure to meet care norms appears to be very strong. Sometimes explicitly, sometimes implied, it was mentioned that people are very conscious of the Turkish community "looking over their shoulder". The internal social control appears to be significant, and there is little scope for deviation from the expectations, even if informal care is no longer a tenable option, for example, if parents suffer from dementia.

Regarding how children feel when they cannot fulfil the care expectations:

Embarrassed about it, because the neighbourhood can see it as well, of course. And very sad because of this. (I8)

The feeling of guilt goes much deeper than one would think at first. Often the children leave here crying [...] because they are being confronted. And the confrontation often is not that unconscious, because the parents often want to rub in how well he or she 
International Journal of Ageing and Later Life

cared for their children and that they had expected the children would care for them as well. (I3)

Yes, because everyone came round to offer their condolences. "How did she die? Did she die at home?" Then one woman said: "No, no, they simply put her somewhere; they abandoned her in a care home, where she died all alone". That "alone", the word "alone" really upset me and it will always stay with me. It was not "alone", I mean, I was there every day for her; I also used to do her laundry in the beginning, and afterwards, it became very difficult, when her dementia became worse, there was no longer any conversation. [...] Yes, when you have a parent in a home, the community treats you like an outcast. We also have a female friend who put her father in a home, and she was given a very rough time. [...] So it is still somewhat of a taboo to place your parents in an old people's home. (I4)

The social pressure experienced, and the feelings of shame and guilt when not being able to fulfil the expectations, can be so immense that they cause health problems:

I had a lot of stress back then. I even took antidepressants for a period of six months. I went to the GP and told him that I could no longer handle it. He asked me if he needed to give me a prescription and I broke down and cried. (I6)

Even health professionals are exposed to the social pressure. Nurses told us certain patients would ask them not to tell anyone that the nurses wash them, out of shame for the children not doing so themselves. One nurse even said she had been put under pressure to not even declare her services on the health insurance for this reason. General practitioners told us that some of their patients of Turkish origin would not even dare to tell them during a visit that they worry about not being able to cope with the care tasks for fear of the community finding out.

Interestingly, these care norms do not stem from socialisation through exposure of the second-generation Turkish migrants to elder care at a young age. As pointed out by several interviewees, the second generation, born in Belgium, grew up in a community without older individuals. That means that there were no examples of elder care around them in their youth. As a result, the first generation's image of "Turkish" elder care is based on the experience they had with elder care in Turkey before they migrated to Belgium in the 1960s and 1970s; and the second generation only learned about what this "Turkish" elder care is like through the 
Negotiating informal elder care, migration and exclusion

stories of their parents. In other words, the first generation got to define the norms, despite these norms being out of date in Turkey today, according to some of our interviewees.

It forms part of the culture, the age-old tradition, that children look after their parents. It has changed by now in Turkey, but we continue to hold on to that culture. (I7)

Rather than affecting informal care directly, we argue in the following that norms shape power positions in elder care negotiations. These care norms give power particularly to the first-generation Turkish immigrants in need of care, mainly at the expense of second-generation women, through social pressure and the risk of being shamed or isolated within the community when not following these rules - that is, through social exclusion based on gender norms.

\section{Rational Choice Institutionalism and Exclusion}

In rational choice institutionalism (Hall \& Taylor 1996, 2007; March \& Olsen 1989, 2006), rational, calculating and utility-maximising individuals collectively decide on the introduction of laws and policies in instances where collective action allows individuals to achieve something they cannot do on their own. Here, the concept of institutions is usually employed with regard to formal institutions, particularly laws and policies. If we combine this perspective with sociological institutionalism, it could be argued that norms in the community shape individuals' preferences, which they would then try to pursue through policymaking (De Tavernier 2016). This process of collective action influencing policies and law, however, requires political participation, as non-participating individuals will not have their concerns taken into account. This means that a social group with diverging preferences resulting from different normative frameworks will not see its concerns reflected in policies if it does not actively participate in the political process. Furthermore, the calculating individuals in rational choice institutionalism - such as the ones in rational choice theory - also use these policies in a rational way in order to fulfil their preferences.

Two aspects of policies are important in this regard: are policies available that allow individuals to pursue their preferences, and are they accessible? A key assumption in relation to availability is full information 
International Journal of Ageing and Later Life

(Pfau-Effinger 2005): a person cannot make use of a policy they do not know about. For an individual to also make use of the policy, moreover, it should be accessible to that individual. Exclusion is present in both the policymaking and the policy-using phase of rational choice institutionalism, which has repercussions for the supply of informal care.

Civic exclusion (Walsh et al. 2017) entails the under-representation of certain social groups in political processes. Despite the municipality making an effort to boost citizen participation and the co-creation of services, individuals from the Turkish community - in particular those of the first generation - tend to be absent from these initiatives. A civic platform debating local challenges, for instance, was joined by 450 citizens of the municipality, yet according to one civil servant we interviewed, none of the participants was a first-generation immigrant.

Especially when social groups have diverging preferences, policies will not or insufficiently take their concerns into account. Therefore, the policies agreed on will be of less use to them. The lack of involvement in political processes can also result in having less information about the policies, harming the assumption of full information on which the availability aspect of policies is based. Hence, civic exclusion results in exclusion from services (Walsh et al. 2017).

What this means for elder care becomes very clear when including data about immigrants. Because of lower political participation of these groups (Aleksynska 2011; Just et al. 2014), little attention is paid to their concerns in relation to elder care. Accordingly, the regulations in place and the professional elder care on offer do not cater to the specific needs of this group of elderly and do not properly match what they consider to be appropriate care. For example, alterations to homes so as to accommodate three-generation households, common in the Turkish community once older individuals are in need of care (Luyten et al. 2016), often conflict with regulations concerning spatial planning. Several interviewees indicated that they had asked for permission to adapt their homes to that end but were not granted permission to do so.

Then we proposed to build a bedroom, shower and toilet in our home, but we did not get permission from the municipality. The bathroom was particularly a problem. [...] There are people who do want to care for their parents, but they inhibit this. (I6) 
Negotiating informal elder care, migration and exclusion

Indeed, several studies indicate that policies often ignore the religious demands or cultural norms of minority groups (Ahmad \& Atkin 1996; de Graaf \& Francke 2003; Hootsen et al. 2013; Lindblad \& Mølgaard 1995: 73). The consequences of migration itself might also contribute to immigrants making less use of their social rights, such as professional care services. Many immigrants have difficulties speaking the host society's language (Burger 2008; de Graaf \& Francke 2003; de Graaf et al. 2012; Yerden 2013: $54)$ and have social networks that are largely confined to other immigrants (Heath \& Demireva 2015; Ministeriet for Flygtninge, Indvandrere og Integration 2007; Muttarak 2015), resulting in them lacking the social resources to exercise their rights (Torres 2012). Limited language skills and networks contribute to immigrants on average being less aware of elder care benefits and services and their entitlement to them (de Graaf et al. 2012). The lack of knowledge about policies and limited language skills hamper both the availability and accessibility of elder care services. Insufficient access to adequate professional care is likely to result in a stronger reliance on informal care.

The interviews contain numerous examples to illustrate this account of rational choice institutionalism and the exclusion of older people with migrant backgrounds. Reference was made in particular to ignorance about the available range of support services or options for professional care at home, including problems arising from the language barrier: for example, not being able to read leaflets or newsletters, an inability to take part in Dutch questionnaires over the Internet, barely attending any activities at service centres and so on. While policymakers lamented "we have really tried everything we could to reach them, but with little success", interviewees from the immigrant community pointed out that one cannot expect older immigrants to complete an online questionnaire in Dutch. Both assuming that they can speak Dutch and that they are able to use the Internet is wrong, in their opinion. Further, they also indicated that the Flemish legislation obliging local authorities to communicate in Dutch does not make things easier for municipalities with large immigrant communities.

At the same time, several interviewees referred to the combination of language, linguistic subtleties, complex eligibility conditions for carer's allowances and occasionally complicated forms as the reason why the 
International Journal of Ageing and Later Life

help on offer is underused. People are far too keen to consider all the obstacles to be language related.

Don't get me wrong, a large proportion of the immigrant population understand the language, but sometimes not in sufficient detail to pick up the finer details and to make a difference. It is all very fragmented and so different, and dependent on the carer's income and on the older person's degree of dependency. (I8)

It is clear in any case that available financial allowances or support services are not always taken up. A striking example, an interviewee told us, is that in 2015, less than 20 people of Turkish origin submitted an application for the $€ 50$ monthly informal carer's allowance available from the city of Genk, out of a total of approximately 570 case files, whereas the proportion of informal carers of Turkish origin is far greater (Luyten et al. 2016). Local initiatives to fight loneliness and inform senior citizens often remain inaccessible because of the language barrier. Furthermore, citizens of Turkish origin also remain absent from the meetings for informal carers organised by the city. Several years ago, the city organised these meetings specifically for people of foreign origin, but the initiative was discontinued because of the very limited interest shown.

In sum, much like norms, policies set the boundaries within which care negotiations take place. Because of a lack of representation, the voices of immigrant communities are often not heard when developing care policies. As the resulting policies might be culturally inappropriate, immigrant communities are left to their own devices to deliver care. Furthermore, knowledge and language barriers hamper access to existing services: because people are not aware of the services or are not aware that they are entitled to them, or because they have difficulties communicating their needs to the service providers. Hence, civic exclusion and exclusion from services in immigrant communities in general, and in particular among first generation immigrants, generate a stronger dependence on informal care.

\section{Rational Choice Theory and Exclusion}

The third theory, rational choice theory, takes the same rational and calculating individual as its starting point as rational choice institutionalism. 
Whereas the latter concerns the relationship between individual decisions and external regulations, rational choice theory concerns the individual, and how considerations of income and time use play a role in decisions about elder care. Within this framework, we can expect that people in economically precarious circumstances, such as the unemployed or those on a very low wage, will be more inclined to take up care duties, particularly if professional care is expensive. After all, the opportunity cost of providing care (lost wages) is low for them. Exclusion from the economy can therefore lead to a greater provision of informal care.

The theory states that calculating individuals maximise their utility by balancing considerations of time outside (paid) work and income (Hakim 2000). From this perspective, individuals outside the labour market or low-income earners can decide to give informal care, as the "opportunity cost" for doing so is low; that is, if the difference between abandoned labour income and saved professional care expenses is small (Blau et al. 2010: 89). Hence, to a large extent the accessibility of policies is determined by their affordability: the lower the cost of professional care, the less likely that it will make sense economically to leave paid work in order to take up informal care. Here, economic exclusion (Walsh et al. 2017) would lead to increased engagement in informal elder care: the opportunity cost of giving informal care is lower for those who are not in employment or are in low-paid jobs. Indeed, several studies find that women with higher earnings potential are more likely to choose to be in paid work rather than taking up a primary role as an unpaid carer (Attanasio, Low \& Sánchez-Marcos 2008; Blau \& Kahn 2007; Cloïn et al. 2011; James 1992). Given the lower employment rates and wages among immigrants in general and immigrant women in particular - for a number of cultural, practical and discriminatory reasons (Cheung 2015) - it might seem rational for immigrant women to choose to become an informal carer as a result of economic exclusion.

In comparison with the other two theories, the interviews provided fewer explicit examples in line with rational choice theory. There is also a risk of social desirability bias: some probably do not consider it appropriate to mention time and money when discussing care for their parents. However, a few of the statements indicated that the cost of professional care is weighed off against the opportunity cost for the informal carer: 
International Journal of Ageing and Later Life

\begin{abstract}
We would also like the help of a cleaner. [...] Life has become far more expensive. Everything costs a lot of money; I also need help for myself. Service vouchers have become more expensive: 10 euro. Work it out: three hours of cleaning already adds up to 30 euro. Granted, you get a small tax refund, but it isn't much, is it? (I9)
\end{abstract}

Who takes up care for the parents? Yes, it is the daughters who are housewives. And who then actually also have most time for this. [...] The one who is free throughout the day does the daily tasks, the ones who work throughout the day still go to the parents in the evenings. (I10)

That happens everywhere, also with the Belgians: if either of the two is temporarily unemployed, that person is expected to do the housework, so it also applies to them. If they're at home, they are also expected to help out more. (I11)

What makes the situation even harder is that the first generation needs help at a relatively early stage: the men because of the work they did in the mines, whereas obesity and diabetes are rife among older women in the Turkish community according to the health professionals interviewed. This means that informal elder care coincides with childcare. One interviewee indicated she felt stuck between her financial obligations for her children's studies and having to take a career break (a system of care leave on a relatively low replacement income) to look after her parents:

But I also have two children in the education system, so you cannot keep it [the career break] up forever. [...] Then my oldest sister came over from Turkey to look after my parents for three months. [...] But when her visa expired, she was forced to go home. (I6)

The assumption that individual action is fundamentally rooted in rationality, the basis of rational choice theory, does not always match reality. Rather than unemployment increasing the likelihood of becoming an informal caregiver, one interviewee talked about how stress related to losing a job actually had the opposite effect: after the closure of a car production plant, some people could no longer cope with the same care demands as they did before, because of the stress resulting from increased insecurity.

People bought their home, carried out alterations to it. The mortgage is still running, the loans carry on. Well, then - all of a sudden - the factory shuts down. [...] people no longer knew how they were supposed to get by. They were panicking: "How on earth are we supposed to manage?" [...] in addition, they have parents who need looking 
Negotiating informal elder care, migration and exclusion

after. What choices do they have? It comes as a shock for them. For years, they managed on their own and adjusted their lives around it. (I7)

\section{Conflicting Expectations and Negotiating Care}

As stated before, these three theories can lead to conflicting expectations about informal elder care. For instance, individuals might forego a particular social right if they perceive it as being in conflict with their normative framework. Moreover, the normative frameworks of individuals can also conflict, for instance if the care receiver and (potential) caregiver have incongruent expectations of how the care should be given. Hence, rather than using these theories to explain concrete care outcomes, it would make more sense to conceive of these theories as factors determining the positions and power relations in the processes of negotiating care.

Because care by definition involves at the very least two people, a caregiver and a care receiver, care decisions are made together, requiring negotiation (Zechner \& Valokivi 2012). In these negotiations, the considerations following from the three other theoretical approaches come together. Earlier studies have already used the "negotiating care" framework to explain outcomes from the three different strands of research separately: McGraw and Walker (2004) discuss it from a cultural perspective, in which negotiation is based on the norms and values of mothers and daughters; Zechner and Valokivi (2012) take the policy perspective, in which eligibility to services is the topic of negotiation; and Conlon and colleagues (2014) go deeper into how socio-economic differences affect elder care negotiations, showing how Irish middle- and upper-class women have more "wiggle room" in negotiating elder care, whereas working-class women do not have this opportunity. However, we contend that the negotiation framework is particularly useful to tie together the three theoretical traditions in policy studies on elder care.

Cultural norms influence who is involved in elder care negotiations, which positions they take in these negotiations and the power relations between the negotiating partners, ultimately affecting elder care decisions. Culture itself becomes a topic of negotiation (Ahmad 1996; Mørck 1998). Because the norms of second-generation immigrants are closer to those of the host society they grew up in (de Valk \& Schans 2008; Kucukcan 1998; Mørck 1998), a daughter's self-perceived role of income 
International Journal of Ageing and Later Life

earner may conflict with her role of caregiver as perceived by her parents (de Graaf \& Francke 2003; de Graaf et al. 2012; Heath \& Demireva 2015; Yerden 2013: 32).

Norms set the playing field and contribute to the allocation of power positions in these negotiations: norms reduce options and shape power relations in the negotiations on how care should be organised. An important factor here is the extent to which specific norms are spread in the community, and the willingness of the latter to sanction those not complying with them. In the Turkish community studied, norms give parents in need of care a strong negotiating position. Lacking a generation of older people in the immigrant community before them, the first generation set the norm of family care as "good" care, and their children - and in particular daughters - may feel social pressure to conform to this norm. Hence, social exclusion or the fear thereof weakens the bargaining position of second-generation women.

As knowledge about and access to professional care services is more limited in the community, families with immigrant backgrounds are in a weaker position to negotiate with professional care providers. Limited language skills among first-generation immigrants and their reliance on their children as intermediaries between them and the state or professional care providers (Ahmad 1996; Burger 2008; de Graaf \& Francke 2003; de Graaf et al. 2012; Lindblad \& Mølgaard 1995: 72; Yerden 2013: 54), exacerbated by language laws prohibiting civil servants to communicate in any language other than Dutch, give more negotiating power to the children taking up this role.

Lastly, employment and income can also be a source of power: in situations with multiple possible caregivers, the relative size of the opportunity costs of giving care for each of them is likely to be taken into account. Hence, wealthier siblings or those with a higher income will have more power to avoid assuming the responsibility for care. It is clear from the interviews with various interviewees that each one of the three aforementioned theoretical perspectives is insufficient to describe the reality of "negotiated care" on its own but that aspects of the three form part of the negotiated care in a complex manner. These negotiations are therefore not solely about care but also about issues of employment and income. 


\begin{abstract}
All of us are working full-time. So my parents have 10 people, which is 5 children plus our 5 partners, which is 10 people, in fact, who can look after them when they need care. However, none of those 10 people is free; we are all working full-time. [...] So one of us would need to take a career break, in that case. Well, I cannot really see it happening. (I12)
\end{abstract}

Everyone has their own financial problems. I also have a family. Sometimes it is really difficult. My mum also has financial problems. And I am also not always able to arrange these things. That is sometimes somewhat difficult. (I9)

There were five children and that woman was thinking: "Why should we do that?" So the daughter-in-law didn't want to, but then he [her husband] really banged on the table with his fist and told her that he would not abandon his mother. So in the end it happened anyway. (I6)

The interviewee who gave the former example also indicated that she ended up taking the main responsibility for the elder care through a process of elimination, despite the fact that she was in paid employment. On the one hand, there is a cultural expectation that daughters - not sons - will provide elder care, and on the other hand the interviewee says that she cannot put pressure on her sister, who is struggling with mental health issues.

I cannot expect that my brothers will do it [take a career break] because both of them have their own family, so they need to work; well, that is our culture, after all. My youngest sister had depression years ago, so I cannot put her under pressure, either. [...] It means that I am the only one left. (I6)

Accordingly, difficult considerations have to be made, balancing cultural and economic concerns and therefore also different risks of exclusion: social and economic. In a community with strong familial care norms, children - and in particular daughters - could be faced with the choice between securing their income and possibly facing rejection by the community on the one hand, and supplying informal care at the cost of economic marginalisation on the other.

We did not interview any first-generation immigrants, which means that an important voice is missing in this story of "negotiated care". However, negotiations not only take place between parent and child but also 
International Journal of Ageing and Later Life

between the different children and their partners about the care to be provided.

And Daddy wanted to arrange things so that we could go live there, but my husband didn't really want that, because we also have our own life. (I6)

And then a very big fight emerged. My sister has a husband; she does not have two children. I have no husband, but I do have two children I have to care for. So she is able to take care of mom. Hello, I work full-time. "But you don't have a husband", she said. (I4)

Often there is always one person who does less, one person who does more, yes, and after a while that leads to clashes: "Look, they are parents of the both of us; I am responsible for so much, why don't you do it?" Or someone who doesn't do anything, who stays aloof, that causes a lot of stress between the children. (I2)

Once again, this case demonstrates that the decision on whether to provide informal care can be a choice between social and economic exclusion: are you prepared to lose a major part of your income in order to comply with the social norms?

Another example concerns the seemingly contradictory messages from the government. The government's plea - phrased in gender-neutral terms - to allow parents to live at home for as long as possible with the support of informal carers may impact the labour market position of women. The government conducts a policy of labour market activation and it strongly believes in emancipation and integration by means of labour market participation. At the same time, the government's appeal to take up informal care duties can take a foothold in the conviction, present in the immigrant community, that wives and daughters have a particular duty to take on informal care. Because labour market participation in the public realm generates a better social status than informal care in the private realm, the decision to provide informal care not only weakens the financial and economic position of women but also their social position.

\section{Discussion and Conclusion}

In this article, we have explored the role exclusion plays in the emergence of informal caregiving. In all three theories commonly used in social policy literature to explain informal care outcomes, exclusion turns out to be 
an important cause of informal care taking place. In particular, exclusion or the risk thereof shapes power relations, revealing a complex picture of intersectionality between migration background, gender, generations and economic status. Social exclusion is the social sanctioning mechanism applied if individuals do not live up to the shared norms within the community. Hence, it serves as an instrument to guarantee that children, particularly daughters, take up informal care responsibilities in a community with strong filial care norms. These norms strengthen the bargaining power of first-generation immigrants in need of care, often at the expense of second-generation women: the risk of social exclusion may be a motivation to take responsibility for one's parents' care needs.

Immigrants' civic exclusion, particularly for the first generation, leads to a lack of available professional care services they consider appropriate. Moreover, a lack of knowledge about and inability to communicate with professional care providers contribute to the exclusion of the first generation from service use. Both knowledge and political participation is concentrated at the core of the community studied here, a core consisting mainly of men. Information might not reach those more in the periphery of the community, disproportionately women, and their voices might not reach policymakers. Hence, within the rational choice institutionalist framework, the exclusion of individuals with a migration background, and in particular women and first-generation immigrants, makes them more reliant on family care.

Lastly, economic exclusion, particularly exclusion from the labour market or by working in low income jobs, affects informal care from a rational choice perspective, because economic exclusion lowers the opportunity cost of engaging in caregiving. From our interviews, this mechanism particularly seems to shape power relations between siblings. Indeed, it is easier for higher-income individuals to escape responsibility. Bringing all three mechanisms together, in the immigrant community studied, family care strongly relies on daughters or daughters-in-law. Daughters who are not employed or in precarious employment in particular feel pressured by their environment to take up the lion's share of care responsibilities towards their parents. Hence, informal care takes place within relations of exclusion, and women are most likely to take up informal care, because they are most at risk of different types of exclusion, whether this is social exclusion when not living up to norms or economic exclusion through 
International Journal of Ageing and Later Life

precarious positions in the labour market. Both of these risks of exclusion are more pronounced within immigrant communities.

Even though we find some support for the rational choice theory, the study points to two important problems with its basic assumptions when applying it to informal care supply. Firstly, not all individuals might respond to unemployment by taking up informal care tasks as the theory prescribes: financial insecurity linked to unemployment can cause problems in coping with informal care. Moreover, the interviews contain many references to emotion: fear, warmth, uncertainty, gratefulness, guilt, dignity, shame, love, a desire for recognition, being misunderstood, being put under pressure, indignation and so on. People were also talking in an emotional way, sometimes fiercely, sometimes with ambiguity, in relation to their own parents, siblings, the migrant community and the "host community". It became abundantly clear from our research that negotiations about how to organise the care for older relatives occur in a less rational way than the theories make it out to be.

Secondly, the relational nature of care does not match well with the atomic social view of rational choice theory, and by presenting caregiving as a "choice" or a "decision", the negotiating aspect of care is negated. Even when care is given by those with the lowest "opportunity costs" for doing so - those with little or no income from employment, as rational choice theory would suggest - these individuals may have been pressured into caregiving by their environment. Hence, words such as "choice" and "decision" hide the underlying power relations and pressure that may have contributed to the outcome. Accordingly, the study is a clear illustration that informal care cannot be examined without an intersectional approach analysing the complex network of power relationships at play.

This does not mean that there is little agency involved in informal elder care supply. Quite the opposite. We interviewed engaged individuals actively looking for solutions to meet the care needs of their parents and trying to find out how they would contribute to caring, as well as professionals trying to circumvent restrictive language laws and searching for ways to organise care, acceptable to all parties involved. Indeed, agency is at the core of any negotiation process in which different concerns are 
balanced. However, it is clear how social positions and the power relations between them shape the framework within which negotiations take place. Because the regulatory framework is far from the only concern taken into account in these negotiations, it might prove difficult for governments to shape informal elder care outcomes. Instead, governments can play an important role as a facilitator, offering options and mitigating the negative effects of informal care provision by supplying economic and social support for informal caregivers, so as to avoid caregiving further exacerbating inequalities.

In this article, we argue that exclusion plays an important role in informal caregiving. However, we could go one step further and argue that exclusion, or at least inequality, is a necessity for care, at least if the state provides little support. Providing care is a very time-consuming activity, and it is therefore expensive: either in direct costs or in opportunity costs. Hence, unless the state funds care, its provision requires either strong economic inequalities, so that rich people can bring in low-wage care workers, or strong social inequalities. Gender norms play a crucial role in the latter case. By making it a moral obligation for women to take up informal care, with non-compliance possibly sanctioned by social exclusion, the community guarantees care provision by circumventing the problem of the high cost of care. Accordingly, inequality effectively becomes a resource for care. Even though this logic would in principle apply to all settings within which informal care takes place, this would be particularly the case in immigrant communities, where the processes of exclusion are much more pronounced.

Whether exclusion is a necessity for (informal) care, or "merely" a mechanism triggering informal care supply, this article is a warning for policymakers seeking to push elder care responsibilities back to the family. For this strategy to be successful, inequalities will have to be exacerbated, be they social, civic or economic inequalities. Only if policymakers take up their responsibility by offering full and particularly fair maintenance of care provision can elder care be supplied in a less excluding way. However, we are aware that community-embedded norms and values may remain a troublesome hurdle. It is up to future research to explore the relationship between exclusion and care further, and in particular the thesis regarding "inequality as resource for care". 
International Journal of Ageing and Later Life

\section{Corresponding Author}

Veerle Draulans, Centre for Sociological Research, Katholieke Universiteit Leuven, Parkstraat 45 bus 3601, Leuven, Belgium. Email: veerle.draulans@kuleuven.be.

\section{References}

Ahmad, W. I. U. (1996). Family obligations and social change among Asian communities. In W. I. U. Ahmad \& K. Atkin (eds.), "Race" and Community Care (pp. 51-72). Buckingham: Open University Press.

Ahmad, W. I. U. \& Atkin, K. (1996). "Race" and community care: An introduction. In W. I. U. Ahmad \& K. Atkin (eds.), "Race” and Community Care (pp. 1-11). Buckingham: Open University Press.

Aleksynska, M. (2011). Civic participation of immigrants in Europe: Assimilation, origin and destination country effects. European Journal of Political Economy 27(3): 566-585.

Attanasio, O., Low, H. \& Sánchez-Marcos, V. (2008). Explaining changes in female labor supply in a life-cycle model. American Economic Review 98(4): 1517-1552.

Berger, P. \& Luckmann, T. (1966). The Social Construction of Reality: A Treatise in the Sociology of Knowledge. London: Penguin.

Blau, F. D., Ferber, M. A. \& Winkler, A. E. (2010). The Economics of Women, Men, and Work. Upper Saddle River, NJ: Pearson.

Blau, F. D. \& Kahn, L. M. (2007). Changes in the labor supply behavior of married women: 1980-2000. Journal of Labor Economics 25(3): 393-438.

Burger, I. (2008). Zijn de care-voorzieningen klaar voor de groeiende groep Turkse en Marokkaanse ouderen in Den Haag? Een literatuurverkenning [Are care facilities ready for a growing group of Turkish and Moroccan elders in The Hague? An exploration of the literature]. Epidemiologisch Bulletin 43(2/3): 13-29.

Bywaters, P., Brady, G., Bunting, L., Daniel, B., Featherstone, B., Jones, C., Morris, K., Scourfield, J., Sparks, T. \& Webb, C. (2018). Inequalities in English child protection practice under austerity: A universal challenge? Child \& Family Social Work 23(1): 53-61.

Cheung, S. Y. (2015). Ethno-religious minorities and labour market integration: Generational advancement or decline? In A. Heath (ed.), 
Negotiating informal elder care, migration and exclusion

Migrants and Their Children in Britain: Generational Change in Patterns of Ethnic Minority Integration (pp. 140-160). Abingdon: Routledge.

Chiao, C.-Y., Wu, H.-S. \& Hsiao, C.-Y. (2015). Caregiver burden for informal caregivers of patients with dementia: A systematic review. International Nursing Review 62(3), 340-350.

Clö̈n, M., Keuzenkamp, S. \& Plantenga, J. (2011). A matter of culture and cost? A comparison of the employment decisions made by mothers with a lower, intermediate and higher level of education in the Netherlands. Work, Employment and Society 25(3): 468-486.

Conlon, C., Timonen, V., Carney, G. \& Scharf, T. (2014). Women (re)negotiating care across family generations: Intersections of gender and socioeconomic status. Gender $\mathcal{E}$ Society 28(5): 729-751.

Crenshaw, K. (1989). Demarginalizing the intersection of race and sex: A black feminist critique of antidiscrimination doctrine, feminist theory and antiracist politics. University of Chicago Legal Forum 1989(1): 139-167.

Dahlberg, L. \& McKee, K. J. (2016). Living on the edge: Social exclusion and the receipt of informal care in older people. Journal of Aging Research 2016: 1-10.

de Graaf, F. M. \& Francke, A. L. (2003). Home care for terminally ill Turks and Moroccans and their families in the Netherlands: Carers' experiences and factors influencing ease of access and use of services. International Journal of Nursing Studies 40(8): 797-805.

de Graaf, F. M., Mistiaen, P., Devillé, W. L. J. M. \& Francke, A. L. (2012). Perspectives on care and communication involving incurably ill Turkish and Moroccan patients, relatives and professionals: A systematic literature review. BMC Palliative Care 11: 17.

De Tavernier, W. (2016). The family as provider of welfare: The role of gender and the family in welfare opinions, preferences, actions and outcomes. Ph.D. thesis. Aalborg: Aalborg University Press.

de Valk, H. A. G. \& Schans, D. (2008). “They ought to do this for their parents": Perceptions of filial obligations among immigrant and Dutch older people. Ageing \& Society 28(1): 49-66.

de Vries, K. M. (2015). Transgender people of color at the center: Conceptualizing a new intersectional model. Ethnicities 15(1): 3-27.

Durkheim, E. (1964). The Division of Labor in Society. New York: The Free Press. 
International Journal of Ageing and Later Life

Greenwood, N., Mezey, G. \& Smith, R. (2018). Social exclusion in adult informal carers: A systematic narrative review of the experiences of informal carers of people with dementia and mental illness. Maturitas 112: 39-45.

Gregory, A., Mackintosh, S., Kumar, S. \& Grech, C. (2017). Experiences of health care for older people who need support to live at home: A systematic review of the qualitative literature. Geriatric Nursing 38(4): 315-324.

Hakim, C. (2000). Work-Lifestyle Choices in the 21st Century: Preference Theory. Oxford: Oxford University Press.

Hall, P. A. \& Taylor, R. C. R. (2007). Political science and the three new institutionalisms. In B. G. Peters \& J. Pierre (eds.), Institutionalism, Volume 1 (pp. 169-193). Thousand Oaks, CA: Sage.

Hall, P. A. \& Taylor, R. C. R. (1996). Political science and the three new institutionalisms. Political Studies 44(5): 936-957.

Heath, A. \& Demireva, N. (2015). Has multiculturalism failed in Britain? In A. Heath (ed.), Migrants and Their Children in Britain: Generational Change in Patterns of Ethnic Minority Integration (pp. 161-179). Abingdon: Routledge.

Hootsen, M. M., Rozema, N. \& van Grondelle, N. J. (2013). Zorgen voor je ouders is een manier van leven: Een kwalitatief onderzoek onder mantelzorgers van Turkse, Marokkaanse en Surinaamse ouderen met dementie [Caring for your parents is a way of life: A qualitative study among informal carers of Turkish, Moroccan and Surinamese elders with dementia]. Utrecht: Pharos.

James, S. (1992). Taxation and female participation in the labour market. Journal of Economic Psychology 13(4): 715-734.

Just, A., Sandovici, M. E. \& Listhaug, O. (2014). Islam, religiosity, and immigrant political action in Western Europe. Social Science Research 43: 127-144.

Koops, H. \& Kwekkeboom, M. H. (2005). Vermaatschappelijking in de zorg: Ervaringen en verwachtingen van aanbieders en gebruikers in vijf gemeenten [Socialisation in care: Experiences and expectations of suppliers and users in five municipalities]. Den Haag: Sociaal en Cultureel Planbureau.

Kucukcan, T. (1998). Continuity and change: Young Turks in London. In S. Vertovec \& A. Rogers (eds.), Muslim European Youth: Reproducing Ethnicity, Religion, Culture (pp. 103-131). Aldershot: Ashgate. 
Lee, Y., Hong, P. Y. P. \& Harm, Y. (2014). Poverty among Korean immigrant older adults: Examining the effects of social exclusion. Journal of Social Service Research 40(4): 385-401.

Leitner, S. (2003). Varieties of familialism: The caring function of the family in comparative perspective. European Societies 5(4): 353-375.

Lindblad, P. \& Mølgaard, M. (1995). Hvad met os? Etniske minoriteter - en udfordring i fremtidens xldreomsorg [What about us? Ethnic minorities - a challenge in future elder care]. Frederikshavn: Dafolo Forlag.

Lowenstein, A., Katz, R. \& Daatland, S. O. (2004). Filial norms and intergenerational support in Europe and Israel: A comparative perspective. Annual Review of Gerontology and Geriatrics 24(1): 200-223.

Luyten, D., Emmery, K. \& Mechels, E. (eds.) (2016). Zoals het klokje thuis tikt, Samenhuizen van volwassen kinderen met hun ouders [No place like home, Cohousing of adult children and their parents]. Antwerpen-Apeldoorn: Garant.

March, J. G. \& Olsen, J. P. (1989). Rediscovering Institutions: The Organizational Basis of Politics. New York: The Free Press.

March, J. G. \& Olsen, J. P. (2006). Elaborating the "New Institutionalism". In R. A. W. Rhodes, S. A. Binder \& B. A. Rockman (eds.), The Oxford Handbook of Political Institutions (pp. 3-20). Oxford: Oxford University Press.

McGraw, L. A. \& Walker, A. J. (2004). Negotiating care: Ties between ageing mothers and their caregiving daughters. The Journals of Gerontology: Series B 59B(6): S324-S332.

Ministeriet for Flygtninge, Indvandrere og Integration. (2007). Etniske gruppers vxrdier - Baggrundsrapport [Ethnic groups' values - background report]. Copenhagen: Ministeriet for Flygtninge, Indvandrere og Integration.

Muttarak, R. (2015). Generation, ethnic and religious diversity in friendship choice: Exploring interethnic close ties in Britain. In A. Heath (ed.), Migrants and Their Children in Britain: Generational Change in Patterns of Ethnic Minority Integration (pp. 71-98). Abingdon: Routledge.

Mørck, Y. (1998). Gender and generation: Young Muslims in Copenhagen. In S. Vertovec \& A. Rogers (eds.), Muslim European Youth: Reproducing Ethnicity, Religion, Culture (pp. 133-144). Aldershot: Ashgate. 
International Journal of Ageing and Later Life

Middelbos, J. (ed.) (2010). 50 mantelzorgers in Genk ondervraagd [50 informal carers surveyed in Genk]. Genk: OCMW Genk.

Peters, B. G. (2012). Institutional Theory in Political Science: The New Institutionalism. New York: Continuum.

Pfau-Effinger, B. (2005). Culture and welfare state policies: Reflections on a complex interrelation. Journal of Social Policy 34(1): 3-20.

Pfau-Effinger, B. \& Rostgaard, T. (2011). Introduction: Tensions related to care in European welfare states. In B. Pfau-Effinger \& T. Rostgaard (Eds.), Care Between Work and Welfare in European Societies (pp. 1-14). Basingstoke: Palgrave Macmillan.

Poscia, A., Stojanovic, J., La Milia, D. I., Duplaga, M., Grysztar, M., Moscato, U., Onder, G., Collamati, A., Ricciardi, W. \& Magnavita, N. (2018). Interventions targeting loneliness and social isolation among the older people: An update systematic review. Experimental Gerontology 102: 113-114.

Saunders, P. (2008). Social exclusion: Challenges for research and implications for policy. The Economic and Labour Relations Review 19(1): 73-92.

Stad Genk (2018). Genk in cijfers. Werkloosheidscijfers. Toestand op 31.12.2017 [Genk in numbers. Unemployment data. Situation on 31.12.2017]. Genk: Dienst Bevolking.

Sutcliffe, C., Giebel, C., Bleijlevens, M., Lethin, C., Stolt, M., Saks, K., Soto, M. E., Meyer, G., Zabalegui, A., Chester, H. \& Challis, D. (2017). Caring for a person with dementia on the margins of long-term care: A perspective on burden from 8 European countries. Journal of the American Medical Directors Association 18(11): 967-973.

Tõnurist, P. \& De Tavernier, W. (2017). The welfare state in flux: Individual responsibility and changing accountability relations in social services. In T. Christensen \& P. Lægreid (eds.), The Routledge Handbook to Accountability and Welfare State Reforms in Europe (pp. 90-104). Abingdon: Routledge.

Torres, S. (2012). International migration: Patterns and implications for exclusion in old age. In T. Scharf \& N. C. Keating (eds.), From Exclusion to Inclusion in Old Age: A Global Challenge (pp. 33-49). Bristol: The Policy Press.

UNECE (2017). Active Ageing Index Home. Available on https:// statswiki.unece.org/display/AAI/Active+Ageing+Index+Home (Accessed October 10, 2018) 
Van Houtven, C. H., Coe, N. B. \& Skira, M. M. (2013). The effect of informal care on work and wages. Journal of Health Economics 32(1): 240-252.

Walsh, K., Scharf, T. \& Keating, N. (2017). Social exclusion of older persons: A scoping review and conceptual framework. European Journal of Ageing 14(1): 81-98.

Warburton, J., Ng, S. H. \& Shardlow, S. M. (2013). Social inclusion in an ageing world: Introduction to the special issue. Ageing \& Society 33(1): $1-15$.

Yerden, İ. (2013). Tradities in de knel: Zorgverwachtingen en zorgpraktijk bij Turkse ouderen en hun kinderen in Nederland [Tied up in traditions: Care expectations and care practice among Turkish elders and their children in the Netherlands]. PhD dissertation. Amsterdam: University of Amsterdam.

Zechner, M. \& Valokivi, H. (2012). Negotiating care in the context of Finnish and Italian elder care policies. European Journal of Ageing 9(2): 131-140. 